\title{
"Here is the knowledge-where should I put it?" Findings from a study of how knowledge spaces are used within a support group
}

Carstensen, P. H.; Snis, U.

Published in:

IEEE 8th International Workshops on Enabling Technologies: Infrastructure for Collaborative Enterprises, 1999. (WET ICE '99) Proceedings.

Link to article, DOI:

10.1109/ENABL.1999.805205

Publication date:

1999

Document Version

Publisher's PDF, also known as Version of record

Link back to DTU Orbit

Citation (APA):

Carstensen, P. H., \& Snis, U. (1999). "Here is the knowledge-where should I put it?" Findings from a study of how knowledge spaces are used within a support group. In IEEE 8th International Workshops on Enabling Technologies: Infrastructure for Collaborative Enterprises, 1999. (WET ICE '99) Proceedings. IEEE. https://doi.org/10.1109/ENABL.1999.805205

\section{General rights}

Copyright and moral rights for the publications made accessible in the public portal are retained by the authors and/or other copyright owners and it is a condition of accessing publications that users recognise and abide by the legal requirements associated with these rights.

- Users may download and print one copy of any publication from the public portal for the purpose of private study or research.

- You may not further distribute the material or use it for any profit-making activity or commercial gain

- You may freely distribute the URL identifying the publication in the public portal 


\title{
"Here is the knowledge - where should I put it?" Findings from a study of how knowledge spaces are used within a support group
}

\author{
Peter H. Carstensen \\ Technical University of Denmark \\ Center for Tele-Information \\ Denmark \\ e-mail: carstensen@tele.dtu.dk \\ Ulrika Snis \\ University of Trollhättan/Uddevalla \\ Department of Economics and Computer Science \\ Sweden \\ e-mail: Ulrika.Snis@udd.htu.se
}

\begin{abstract}
In order to design useful knowledge media spaces to knowledge workers it is essential that we understand the nature of the work conducted and the knowledge applied in real settings. This paper reports from a study of how a group of quality assurance specialists gather, structure and distribute information and knowledge. Based on the findings a number of overall requirements for knowledge media spaces are identified and discussed. The essential findings were that information and knowledge are created and handled in many different ways and have many different forms. The core issues of our lessons learned so far are that we carefully need to consider knowledge media spaces both in terms of communication channels and knowledge archives. Knowledge media spaces should be seen as spaces in which knowledge and information is exchanged, filed, retrieved, presented and refined by actors having different vocabulary and perspectives on the knowledge. These characteristics must be taken into account when designing IT and multimedia based knowledge media spaces.
\end{abstract}

\section{INTRODUCTION}

It is widely acknowledged that knowledge is one of the most important assets of today's organisations. How to support the company's knowledge-intensive work processes (e.g. quality support, product design or strategic planning) is therefore becoming more and more crucial question in many organisations world-wide. Especially companies that rely on highly skilled employees in complex work domains characterised by flexibility and creativity, the so-called 'knowledge-intensive firms'. Identification and analysis of the knowledge-intensive work processes become essential.

People need to work together in order to create knowledge about the work domain and to provide the capabilities and resources required in complex settings (Schmidt, 1994). Thus knowledge-intensive work activities often concern collaborative problem-solving and support that require a more effective way of handling information and knowledge between different people, both in here and now situations and over long periods of time.
The distributed and dynamic nature of knowledge work possesses a high degree of complexity involving many different actors with different conceptualisations, interpretations, perspectives, needs etc. of the information and knowledge produced and approached. To phrase it differently, the different actors have different perspectives on the concept of knowledge. Thus the work needed to articulate knowledge becomes extremely demanding and complex. Often face-to-face interaction is required and requested. However, in complex and collaborative work settings the problem of articulating knowledge by rich interaction and communication is obvious. There is a need for computer-based mechanisms for interaction and coordination of information and knowledge (cf. e.g., Carstensen, 1997).

Based on a field study addressing a knowledge networking group this paper concentrate on how individuals and groups create, coordinate, and communicate knowledge in different support activities and what mechanisms and artefacts they use in these knowledge work activities. We have analysed central aspect of a quality support group working as knowledge supporters and specialists. Their work activities involve managing information and knowledge from internal as well as external sources and interacting with co-workers as supporters and community colleagues. From the findings in this study we identify problems and needs of the organisational processes, and we use this as input for specifying requirements on potential IT support. It is our assumption that this will be one (of several) fruitful way to discuss how IT and multimedia-based systems can support use, establishment and maintenance of networking knowledge repositories and knowledge media spaces supporting collaboration by allowing distributed interaction and access to shared knowledge spaces.

In the next section our research approach is introduced. Then an overview of relevant aspects knowledge management is provided. The empirical findings are briefly presented followed by an analysis of the characteristics of the knowledge work repositories and activities of the support group. The paper is concluded with a discussion of relevant 
requirements and considerations for computer support applicable to knowledge networking groups.

\section{RESEARCH APPROACH}

Our approach is based on the assumption that in order to obtain a coherent understanding of - and to design ITbased tools for - complex work situations like knowledge work, field studies are essential (see e.g., Keyser, 1992).

This paper is based on data collected in an empirical study of a group of quality assurance experts working in the central quality assurance function at a large Danish pharmaceutical company. The study focused on which information and knowledge the actors gathered, how they organised and structured the information, how it was disseminated, and which means were applied for these activities.

The field study and the preliminary data analysis were conducted over a long period. It was exclusively based on qualitative data collection techniques such as non-participant observations and qualitative semi-structured interviews (Patton, 1980). Documents, on-line archives, paper-based repositories and other means for handling and managing information and knowledge were studied in details. Approximately fifteen semi-structured interviews, five meeting participations, and several direct observations were carried out. In order to obtain a holistic view of the knowledge process interviews with some partners, seen as clients or users ("reveivers") of the support group, were performed as well. To clarify themes and conceptions the material has been discussed with the employees in several informal meetings.

The research approach used in analysing data can be characterised as qualitative research heavily inspired by both Work Analysis (Schmidt and Carstensen, 1990), Competencies at Work (Sandberg, 1994), and by ethnographic approaches to studying work (like e.g., Bucciarelli, 1988). To understand and model the means applied as means for handling the co-ordination the concept of both Co-ordination Mechanisms (Schmidt and Simone, 1996; Carstensen, 1996) and Knowledge Creation and Management (Nonaka, 1995; DeMichelis, 1997; Spender, 1998; Wathne et al, 1998) were used. In processes of managing knowledge, groupware is understood as a technology supporting dispersed people in collaboration through co-ordination, co-operation and communication (Schmidt \& Bannon, 1992). Therefor we in one section describe more specifically such a groupware use as a knowledge mediating means of knowledge harmonisation and dissemination.

Our understanding of knowledge media networking spaces is inspired by several places in the media space literature and includes concepts like Common Information Spaces (Bannon and Bødker, 1997), Media Spaces (e.g., Gaver et al., 1993), Knowledge Management Technologies (Kirn et al, 1997; Glance et al, 1998; Van Heijst et al, 1998). These concepts have been applied as sources for inspiration in the process of identifying relevant requirements for knowledge media networking spaces.

\section{KNOWLEDGE MANAGEMENT AND KNOWLEDGE MEDIA NETWORKING SPACES}

Knowledge management aims at identifying the corporate knowledge in collective memories and facilitating communication and co-ordination between people who actually create it and people who really need it (Wathne et al., 1996). Efforts are intended to retain, analyse and organise employees' expertise, making it easily available anywhere, any time. This is due to the difficulties in finding effective solutions to problems like: Information and knowledge are hidden in the companies document repositories and people's minds; Experts and key persons leave the company with a lot of experience; And the same mistakes are done repeatedly. All these problems refer to the complexity of articulation and communication between knowledge workers who might even be distributed in time and/or space. To meet these problems the concept of knowledge management is considered as the key strategic process in much knowledge intensive companies of today (Spender, 1998).

According to Nonaka (1995) the concept of knowledge can be understood only in combination with the situation in which it is created. In order to become knowledge information must be interpreted and applied in a specific situation by a human actor and hereby be conceptualised to a certain level of abstraction (Sandberg, 1994). This interplay between abstraction and concretion is an essential aspect of the knowledge creation process. Nonaka (1995) addresses the key issue of interaction in this process. He identifies four modes of interaction, which include socialisation, combination, externalisation, and internalisation. In socialisation one individual shares tacit knowledge with another individual. In combination one piece of explicit knowledge is combined with another, i.e. through an artefact. Externalisation refers to the process in which tacit knowledge is made explicit; and internalisation is the process of converting explicit knowledge into tacit.

When identifying the corporate knowledge repositories we can suppose that knowledge consist of e.g. problem-solving expertise in functional disciplines, procedures of know-how, experiences, and lessons learned (Spender, 1998). Those knowledge repositories can be formalised as well as semiformal (like formatted documents) and completely informal representations (for example as what is often termed "tacit knowledge" (Nonaka, 1995). Knowledge will only be formalised if it has reached a certain state of acceptance and stability and if the effort of formalisation will be paid off by application systems that make use of it. Kirn et al. (1997) argue that application of knowledge requires deeply integrated use of all the different types of knowledge. Abilities to manage disparate know-how and heterogeneous viewpoints are essential in order to make it accessible and suitable for all members of an organisation. This will facilitate communication and coordination between people that actually create it and people who really need it. Linking the gaps between creating and using knowledge is a central issue in knowledge transformation (Wathne et al., 1996).

Mentzas \& Apostolou (1998) further develop this processoriented view. They identify the flow of knowledge between people in an knowledge work setting can be defined in a knowledge management process. This process starts with (i) a generating phase, which aims at identifying the desired content of knowledge by creating ideas and discusses contributions among involved actors. It follows by the next phase (ii) organising the knowledge, which aims at finding a suitable scheme in which to represent the knowledge generated. In order to increase and refine its value the third phase is (iii) developing. The fourth phase (iv) distribution 
refers to how people gain access to the knowledge in order to use it. They apply this framework of knowledge management when doing a comparative analysis in consultancy firms.

Alavi (1998) outline another framework of a knowledge management processe that seems to be very useful. It consists of four different phases embedded in an organisational setting with a technological infrastructure included. These phases are; (i) Creating: an important activity seems to be creation of new knowledge. By continuously acquiring new knowledge in problem-solving, decision-making, and training, knowledge creation takes place. (ii) Organising: Knowledge created need in some sense to be synthesised and refined in order to reach a certain level of formalisation. This activity aims at putting the knowledge in such a form that it is accessible to others (iii) Distributing: This activity concerns the way in which the knowledge is communicated among people. (iv) Applying: This activity refers to how and when the knowledge is applied and also to what degree it is embedded in daily work practise. In relation to the previous activities this one is more directed to the individual "receiver" or user of the knowledge.

When talking about IT-support for managing knowledge we should include what has been learnt from the field of expert systems and knowledge-based approaches aiming at conceding a computer what an expert knew in order to support the process of problem solving and decision making in narrow knowledge domains. However, these approaches became highly overestimated and was furthermore reduced to concentrate primarily on validating the "true" knowledge of the rule-based expertise (Firebaugh, 1989). Furthermore, they had no support for collaborative workspaces in which knowledge could be coordinated and distributed among coworkers. This is discussed in details in Snis (1997) based upon a study of how a group of manufacturing workers negotiate what is the best way to organise and carry out complex production tasks and how they manage and structure their knowledge.

Although knowledge management could be seen as an issue in human resource management, or organisational theory, beyond any specific technology questions, there are important aspects of work that can be supported or even enabled by innovative information technology. An interesting approach when talking about groupware support for innovative knowledge management technologies is the media space technology as discussed in the HCI and CSCW literature. The basic idea in the media space research is to support collaboration between different remote people in media spaces. A media space is here understood as a virtual, spatial extension of the room, which is created through a media like a video link and/or an audio link (Gaver, 1993). An essential feature is the informal way in which interaction can take place by noticing or understanding the know-how or activities of other knowledge workers beyond geographical limitations. Gaver (1995) also argue that a media space normally supports mutual awareness among actors or users as it is usually regarded as an open and available technology. In this interpretation of media spaces the interaction takes place as synchronous communication where the sender and receiver are aware of this "established channel" and what happens on it. A typical shared media space scenario seems to be in situations in "real-time" or near real-time.
However, interactions can moreover involve people that are temporarily dispersed. In other words actors who interact asynchronously. A useful approach to knowledge management must thus be elaborated further. Technologies for knowledge management should facilitate synchronous as well as asynchronous interaction between people. A typical situation will be when information and knowledge is put into a common repository at one point and subsequently will be accessed by another co-worker later on. This type of shared workspace is part of what Bannon and Bødker (1997) describe as a "Common Information Space". In common information spaces explicit actions handling inclusion, reuse and refinements are normal, and the actual structure of the structure of the information space itself will be changed and refined during use. According to Bannon and Bødker it is often not agreed what the structure and content should be, only that the production of it may affect its form. Another point that Bannon and Bødker emphasise is the need for refining and posing the content into a useful context. In knowledge transformation it is very important to come to an understanding of the background knowledge and assumptions about the actual context where the knowledge was produced. This discussion is further explored in the field of organisational memory, which has been widely developed during the last decade (Conklin \& Begeman, 1988; Ackerman \& Malone, 1990; Ackerman, 1994; Kutti \& Virkunen, 1994; Kristoffersen, 1996; Conklin, 1996; McDonald \& Ackerman, 1998). It has been argued that common information spaces and organisational memories should also be more abstract tools reflecting a collection of social activities that are performed by skilled worker in the organisation culture (Hughes et al, 1996; Kutti et al, 1998).

In this case it makes sense to relate our understanding of the concept of common information spaces to Nonakas interaction mode "combination" that emphasise a "storagedeliver" metaphor when discussing interaction through artefacts. The artefacts used are seen as the knowledgemediating mechanisms for explicit knowledge exchange. Individuals can exchange and combine knowledge through different media such as documents, meetings, telephone conversations, or computer-based networks. These technologies (e.g. e-mail, groupware packages, hypertext systems, and Intranets or Extranets) have in recent years been on the list of knowledge management efforts (Andreu \& Ciborra, 1998). More specifically, today a number of applications of groupware support tools have been carefully investigated (see e.g., Orlikowski, 1992; Alavi, 1997; Conklin, 1998; Robertson et al., 1998; Ackerman \& Halvorsen, 1998). Work on both document management systems and digital libraries has initiated efforts of knowledge management as well. New web-based application tools provide support for workgroups via collaborative workspace (Huber, 1998; Kirn, 1997). These efforts have turned out to be categorised mainly into two different streams of support: namely the creative learning approach and the capturing and reuse approach. In respect to knowledge management, these are two sides of the same coin and should both be included in knowledge management technologies.

Another key characteristics of a knowledge media networking space is that is should be multi-modal. Different formats of interaction and knowledge must be provided since different types of information require different means for representation. The means for storage and retrieval within an 
asynchronous interaction must be possible in a flexible number of integrated and combined modalities.

To summarise we can say that a knowledge media networking space is - in our understanding - a network of people and resources in a collaborative setting, interacting through and by means of a number of different technologies. These technologies are used as mechanisms that augments and interconnects people and resources so that knowledge can be created, organised, distributed, observed and applied by means of a computer-based collaborative knowledge media space.

\section{EMPIRICAL FINDINGS}

The field study was carried out in a quality support group in a large Danish pharmaceutical company. The quality support organisation in this company is organised into seven different groups. Each of them has their own expertise area. Their main purpose is to support the product supply, development departments, and other sites within the organisation. As a world-wide company these sites are geographically dispersed.

Many regulatory authorities expect pharmaceutical manufacturers to comply with "good manufacturing practice", GMP. In order to deal with this highly regulated and complex industry it is extremely important to provide employees with the necessary knowledge of current GMP.

The quality support group in the current study has special competencies within validation. Seven employees and one manager are included in the group, most of them are chemistry engineers. Generally, validation work can be described as a planned and systematic way to assure collection of quality records, which demonstrates that the entity that is subjected to validation is in compliance with the current GMP requirements. The different entities subjected to validation may include process equipment, computer systems, buildings and utility systems. All these entities have impact on the product quality, identification and documentation as well as process reproducibility.

\section{A network of knowledge workers}

As knowledge workers the employees in this quality support group are typically concerned with developing ideas, interpreting standards, solving problems, and exchanging knowledge. As a support department they depend heavily on the expertise of their employees and engage in value-added activities for their clients. They put considerable emphasis on applied creativity for solving problems of their internal departments. As one of the members of the group stated:

"As a quality support unit our role is to see the different organisational sites as our main clients. But we also act as the extended arm from the regulators and protect the end-client of our products - the patient."

They think of themselves as having at least three different roles. Firstly, they are validation experts. They must know all the GMP requirements about validation work. They need to be fully updated on the on-going modifications in their expert domain, and they in turn seek to change others through reformulating procedures and adjusting them to specific use within their organisation. Secondly, they need to assure quality in the use of GMP requirements. By reviewing and accepting operational documents they assure that validation work is performed in compliance with current regulations. Thirdly, they are supporters. Acting as internal consultants they help operational workers to plan the validation work and to solve problems that occur out in the product supply sites. Two of the employees in the quality support group are actually acting like "flyers". Being a flyer means that you are temporarily located in a "client site" during a rather long period of time, typically involved as a consultant in a project taking place in a product supply unit. It is a popular way of working: Collaborate and being actively participating in the operational units where the problems really occur.

An interesting aspect of the validation support work is that it is not only an individual task. Efforts of turning information into knowledge include both individual as well as cooperative tasks. Nobody can do the job alone. No worker is all-knowing and all-powerful. The actors act and interact on the basis of partial-knowledge and they do not know or have access to the whole picture. In the validation support unit they have to some extent their own area of expertise. This is not clearly defined, but they all know each other's topics and collaborate due to this. This may imply that two of them can be involved in the same "project" and thereby complement each other. Efforts are in this aspect aiming at providing sufficient criteria for applying good manufacturing practices. Collaboration with the product supply departments is crucial as they are the main users "receiving" or rather "using" the knowledge provided by the quality support knowledge worker. As one interviewee put it:

"The problem of having lack of knowledge is solved by the use of procedures. These are in fact the mechanisms assuring that we any time know how to do it."

Information and knowledge distributed by the knowledge workers in quality support is not just taken for granted. For operational knowledge workers applying knowledge requires effort as well. For instance in product supply, applying knowledge has to do with judgements in their daily work activities and to reformulate requirements into their own work procedures and instructions. In practise this means that even highly structured knowledge, such that e.g. procedures written in formal documents, involves a high degree of creativity and experience.

From the above we can observe that cooperative knowledge work is highly complex. A network of knowledge workers is established involving many actors with different perspectives and backgrounds. In order to assure that the validation activities are done correctly, the validation has to be properly planned, co-ordinated and documented in a collaborative effort throughout the organisational process.

\section{A repository of knowledge sources}

The day-to-day work of the specialist group requires people, who are able to extract knowledge "from themselves" as specialists, or from other knowledge sources, output it in a structured form, distribute it, and maintain it over time. In the quality support group interactions are therefor supported by various knowledge sources which represent and store knowledge.

Preferably, most information and knowledge was organised in internal archives, as explicit knowledge in operational documents. An internal procedure states that these operational documents must be organised in a way that 
is applicable directly into work practice. All the documents are managed in their Intranet as a corporate knowledge sharing archive as a means applied for organisation and dissemination of corporate knowledge. Structured and welldefined knowledge work procedures that are in compliance with and sanctioned to the over all good manufacturing practices were represented and stored in mainly two kinds of operational documents: "Requirements" and "Procedures", two different Intranet-based web applications managing documents. One is a knowledge "harmonisation" tool (named "Requirements"). The other one is a quality support system handle the "Procedures". In the following these are referred to as the R-system and the P-system.

\section{The R-system}

The R-system is a tool which the group has decided to use for specific common issues, which could not be part of the more general "Procedures" included in the P-system (described in the following section). The R-system is intended to ensure that work efforts are in compliance to current regulatory requirements and thus aiming at sharing better practices. A core characteristic of one such "requirement" (included as a document in the R-system) is that it must add value to the company, and the responsible actor in the relevant part of the organisation must accept the added value. It must also be recognised and accepted by the users/clients as the standard way of working and thus ensure continuous improvements of the content and quality in their work processes.

The R-system provides functions that enable users or groups of users to design structures of documents to suit their specific needs. Hence, it is the user - the "receiver" of the knowledge - who owns these documents and who is empowered to maintain them in a valid state. The document format is therefor in editable word-files. Standard operational procedures and templates are also included in this format. Accordingly this facilitates the direct applicability to the users. "A requirement" may be divided into two parts. Part one discusses the specific demands and the rationale for a specific interpretation (if any). This part must be adhered to wherever the work described is carried out. Part two of "a requirement" must be written in such a way, that it can be used directly by each site or unit. For specific needs this part can be written as a checklist. If relevant, references can be made to the "requirement", upon which the local implementation is based. By using the Rsystem a certain level of harmonisation throughout quality support is intended to be ensured, and as such this system is conceived as a knowledge harmonisation and dissemination tool. When modifying "a requirement" to meet local needs the result is another document, typically a procedure, which is to be looked upon as a template, "a better practice" and which is handled by the P-system.

\footnotetext{
The P-system

The P-system is the quality system used for the electronic distribution of operational documents, followed from requirements in the $\mathrm{R}$-system. It aims at integrating the quality and business processes. In 1998 there were 6000 documents and it is estimated that there would be about 15000 in 1999. The P-system is Intranet-based and is accessible from all sites in their world-wide organisation The primary target group for the P-system is employees using operational documents as procedures. All documents
}

are stored and indexed in a document management system. When a user wants to view a document, it is fetched from the document management system and presented in the Psystem for non-editable use like viewing, navigating and printing. This non-editable file format is designed only for on-line publishing and is therefor the default format shown in the browser. Some of the documents contain forms and templates that require access to word processors.

Accordingly, the P-system is the application system, containing only index and applicability information. The system filters the documents so that only the relevant subset of documents is listed for a specific department/process/item. The procedures in the P-system can be grouped into four levels:

- Top level - Documents applicable for all departments in the organisation

- Cross functional level - High level documents applicable to many departments or processes

- Department level - Documents assigned to (a) specific department(s)

- Item specific level - Documents related to specific item numbers or analysis numbers

Each document has a "pre-page", which contains added meta-information about the document. This pre-page is in a matrix form and facilitates coordination between actors to which the documents apply. Each department has their own list of applicable on-line documents. In the list document titles are linked to more detailed information.

Another central characteristic of the P-system is that it contains only approved procedures. These are only accessible as long as they are still effective. In order to visualise the status of each document there are coloured icons. A red bullet indicates that the document is issued but still not effective. A bullet saying "new" indicates that the document is issued within the last 14 days while a green bullet state that the document is effective. A yellow one indicates that the document is still effective but the expiry date has been defined.

The problem of who is providing what and who needs what is partly solved in the P-system by a distribution service based on a semi-automated profile mechanism. In a department profile, the units have defined their business areas, processes and functions that are mainly of their concern. This kind of "applicability matrix" is also used when defining a specific profile of a document in the prepage form. By using the same attributes and attribute values they can see to which unit the document is applied. When there is a match between the departmental profile and the document profile a distribution service is provided by the workers at a document control centre. They are responsible for the establishment of the necessary email lists and the execution of the distribution service. This way of distributing knowledge corresponds to a kind of narrow casting. Since each department has defined their profile, this narrow casting is on a departmental level. Each department has a responsible person maintaining the departmental profile and to some extent also knowing a few individual interests, i.e., user profiles.

The use of the R-system and the P-system assures that new knowledge, requirements and operational procedures are in compliance with external regulations as well as expertise in the work domain. All the documents included in the R-system and the P-system play an extremely important role as formal and applicable knowledge sources about how 
to get the job done. These current knowledge-mediating systems facilitate also that knowledge can be transferable and distributed electronically among dispersed co-workers (e.g. managed in the P-system and the R-system). They are adaptable and tailor-made to the needs of different users (e.g. created collaboratively in a co-authoring process and stored in word- format). The systems are furthermore applicable and usable to practitioners, support workers, and management (e.g. used as instruction of know-how in work practice).

In this field study knowledge sources of an implicit form, like for instance experiences and lessons learned from specific problem solving situations or projects, are not commonly recorded. For example, one client calls for a solution to a specific problem and the expert needs to understand the context of this problematic case. Discussions on the phone are continued. Sometimes a phone call may result in a visit to the site where the problem occurred (onsite problem solving). Some times a meeting is arranged. Our analysis indicates that in the quality support group experiences and lessons learned from remote or on-site problem solving are communicated through email or phone calls, but not commonly recorded in shared archives.

External knowledge sources like web-sites of regulatory affairs are used too. Employees search through or subscribe to these external information repositories, where modifications in the global regulatory affairs reflect changes to their expertise area. This acquisition implies that information need to be interpreted and developed in order to be used in the work activities and thus contribute to better practices.

\section{Other means of disseminating knowledge}

One popular way of supporting and distributing knowledge is by holding mini seminars. People from the operational units propose some and others are suggested from the specialist group on topics that they coincide the co-workers need. The validation group strive at looking from the perspective of the users when proposing subject and target group in these mini seminars. The administration of the seminars is supported by a web-application with a related database. From this system the administrator can read submissions for interest in order to anticipate the scope and plan. Apart from the popularity and scope actuality and priority on different seminars can be seen from this computer-based cooperative routine. Power-point presentations and video films are the typical forms of information and knowledge mediating sources.

To announce different seminars and courses email lists are produced. By grouping individuals email messages can be sent out as a reminders. These are usually enclosed with a link to the intranet-based application in which the actual mini seminar is precisely described.

From our field study it can be observed that the interaction between distributed knowledge workers is mainly based on explicit information in contrast to face to face communication (socialisation) in which implicit information and knowledge exchange and dissemination takes place through very rich communicative and informative interactions. This implies that knowledge sources must be available through common knowledge spaces that are tightly coupled to the work procedures.

\section{TOWARDS REQUIREMENTS FOR IT SUPPORT}

This section discuss overall requirements taking departure from an analysis of an organisational unit with a core competence and a knowledge network that links and leverages the diverse repositories and facilitates the collaboration between the people in the organisation. The suggestions are derived from our findings presented above and, of course, inspired by the general discussions of media spaces, common information spaces and computer-supported knowledge management at what their technological potentials are.

In order to meet the specific needs in the field study and the general requirements described in the literature we can summarise that IT support should include both knowledge archives and communication channels. Knowledge archives that are applied and maintained by knowledge workers should have a compound nature supporting somewhat opposite requirements. On the one hand the structures must be simple, stable and fairly rigid in order to support actors with different background and knowledge about the field of work in sharing (generating, maintaining, filing and retrieving) the knowledge. On the other hand, the structures must be open and flexible in order to support the evolving nature of a knowledge media networking space. This conforms with findings from our previous study (cf. Carstensen and Wulf, 1998) and with the findings of Bannon and Bødker (1997) indicating that common information spaces must be open and malleable on the one hand, and immutable on the other. Furthermore, there seems to be a need for structures that can be interpreted, developed and maintained in a decentralised manner by the actors.

The study also indicated that actors accessing shared information are often interested in references to other actors having knowledge about a certain field than in factual information or knowledge. This need refers to the requirement of communication channels. Actors both inside and outside of the knowledge team constitute a network of knowledge workers (the collaborative work arrangement) that must be able to share knowledge in a direct communicative way.

In a little further detail a number of general requirements have been developed:

Requirement 1 - Recording: Recording knowledge and information is a central issue. As argued before the asynchronous aspect of knowledge work is apparent when the knowledge workers are distributed in both space and time. The knowledge workers in our study usually perform activities conducted over a period of time. An important feature is therefor the storage capabilities in which information and knowledge can be easily submitted and commonly shared in a knowledge archive. The knowledge workers in the quality support group were partially supported with such an archive - the R-system - in which knowledge work procedures are maintained.

Further input to such archives could for instance include specifications, case documents, descriptions of state of affairs, experiences from projects, working procedures or outcomes from specific problem-solving scenarios reported from phone-calls and emails. This requirement also includes that cross-references to other entries or other files need to be managed. And it should also be possible to store relevant references and links to people, which leads us into the discussion of the next requirement. 
Requirement 2 - Communication: According to our studies it is not enough to interact through documents and knowledge archives ("combination through artefacts" as Nonaka puts it). There is also a need for facilities that support communication and discussion among co-workers. When analysing the types of information requests formulated by the collaborating actors, the most common type of information request concerned people. Actors search for another actor: 'Who will know something about...' Our interpretation of this is that most actors prefer an 'intelligent' conversation in which the requester gradually can refine his/her understanding of the problem and thereby refine the search request. According to Nonaka this interaction can be understood as socialisation. In order to support the communication process functionality is further needed for establishing knowledge networks like discussion forum and email lists that put experts together.

Requirement 3 - Refinement: Our field study showed that information and knowledge will frequently be refined and changed. The refinement was usually triggered by a new and increased understanding (conceptualisation) of the field of work, i.e., it was triggered by the involved actors. For instance, refinement in the knowledge archive "R-system" should be made easy to reflect actual conceptualised knowledge. Furthermore, this requirement implies that some mechanisms of active (intelligent) distribution that should ease the dissemination of pieces of knowledge, which has been refined, to co-workers who need or are interested in that knowledge must be provided.

Requirement 4 - Annotation: To support the previous requirement a continuous refinement and exploration process of the knowledge should be facilitated by another facility. To explicitly illustrate the dynamism of the knowledge it would be useful if the collaborating actors could add feedback comments to existing pieces of information and knowledge in the repository. The content should not only reflect one knowledge worker's interpretation of a certain piece or a pointer to other places where similar topics are addressed. It should also be easy to add and understand this kind of metainformation in the structure (e.g., judging relevance) so that interdependent actors are able to exchange opinions as well as receive advice and comments. Specifically, in this field study the process of writing "procedures" (authoring documents) is cooperative. Negotiation between the different actors takes place as a reviewing process among co-workers of operators, quality people as well as specialists from the validation group. Support for requests like "Please, give me comments on this document?!" will thus be provided.

Requirement 5 - Classification: According to our studies of knowledge work flexible classifications and indexation structures should be provided. These must enable an evolving structure that adapts to the changing user needs. The structure of a knowledge media networking space evolves over time. Thus, a few guidelines should be obeyed:

- the classification structure must appear simple, and complex structures should be provided in ways so that it can still be inspected at a glance

- $\quad$ in many situations rigid structures are easier to use with predefined classes

The knowledge media networking space should also include classification features making it easy for workers to decide who has the information and knowledge needed for a particular work activity, and who would have interest in which piece of information or knowledge (a kind of applicability matrix or knowledge map). This implies support for managing and handling disparate know-how and heterogeneous viewpoints, and to make it accessible and suitable for all members of the organisation. Also categories of different types of knowledge could be classified in a mixture of non-orthogonal dimensions. This calls for flexible structures that can be partially defined and then be regularly refined. This demand for flexibility has previously been discussed. It is to some extent in opposition to the overall requirement on simplicity and rigidness mentioned previously.

Requirement 6 - Retrieval: Retrieval facilities must be included. It must be easy for individual workers to access the knowledge in the common space of networking repositories and people. The very mass of knowledge as well as its diversity in terms of representations, media, and contents, make retrieval using conventional information access methods difficult. Knowledge media networking spaces should therefor incorporate methods for intelligent knowledge representation and dissemination. Providing access to search for other actors has at least two major implications for the design of common information spaces: (1) structures supporting establishing and retrieving information on 'who knows something about' in the common information space must be provided; and (2) stepwise refinement and partial definition of the problem that is addressed must by supported.

Requirement 8 - Navigation: Knowledge media networking spaces should support environmental scanning for knowledge acquisition and navigation. The specific requirement of putting crucial external information and knowledge on-line is obvious. Our empirical analysis points to the requirement of subscribing to on-line databases, for instance the various external guidelines for GMP-standards. To this an intelligent navigation mechanism could support searching in the amount of various knowledge bases. Incoming news and changes to those repositories should be indicated and pushed to the knowledge workers, too. The knowledge media networking space should support sequential (chronological) searching and browsing. Also, since users are not used to hyper-link structures the use of these needs careful consideration. This is probably only a question of time until the users become familiar with www-searching, etc.

Requirement 9 - Context-sensitive: To come to an understanding of the background assumptions of a specific piece of knowledge it is essential to capture the context of it. In the literature on organisational memory several authors have argued for this requirement (cf. e.g., Ackerman and Halvorsen, 1998; Kirn, 1997). This implies that support should emphasise the means by which knowledge is created in the past to bear on present activities. In order to support coordination of the distributed cooperative activities, the structure of the common information space must support inclusion of information regarding both the work processes and progress. This task may be eased if sufficient meta-data is stored, e.g., the description how a knowledge item was derived, why it is believed to be valid, in which context it holds, or who supports it. In order to be able to re-create a previous case scenario where knowledge typical was produced it should be possible to record the context in which the problem occurred. This refers to the storing requirement, in which it should be possible to capture and record 
information and knowledge that precede a decision "on the fly".

Requirement 10 - Multi-modality: As proposed by Van Heijst et al (1998) knowledge media networking spaces should support highly integrated use of all the different types of knowledge. Computer-based knowledge repositories should not only incorporate plain or formatted knowledge pieces of text. Multi-modal presentation forms would therefor be useful. Our empirical analysis indicates that some of the operational procedures documented in the current information and knowledge archive usually contain descriptions about how to set up equipment and in what way the different components affect its operation. In some cases it could be more useful to present knowledge work that is more implicit and therefor hard to tell and formalise in written procedures.This know-how could for instance be presented as animations or video presentations. Also some seminars or training courses could benefit from videoconferencing technologies or video streams on the Internet.

Requirement 11 - Acceptance: A particular challenge of applying knowledge seems to be the degree of acceptance to the users. Reached to a certain degree of explicit the knowledge should be accepted and then be recorded. What is sanctioned as reliable knowledge in this field study depends on the interpretations and guidelines formulated in the Rsystem and the P-system. The information and knowledge included must be adaptable and tailor-made to the needs of different users in order to be applicable and usable to practitioners, support workers, and management. Another important issue is that they had to trust the content of the knowledge managed in the systems since they had been actively participants in the beforehand authoring process of negotiation and reformulation of requirements and procedures.

From our study we can also understand the acceptance from another point of view. The people involved had a positive attitude towards knowledge media networking spaces in general and it seemed that they understood the importance of sharing their knowledge to others without jeopardising their value as employed specialists. Perhaps the organisational acceptance is of a more cultural issue that also needs to be considered. This has, however, more to do with the organisation and culture than with IT-requirements.

\section{CONCLUSION}

The aim of this study has been to explore knowledge work in a specific field setting in order to identify requirements for design of knowledge media networking spaces. We have presented findings from such a study and discussed what can be learned about the establishment, use and maintenance of such knowledge media networking spaces from observation on how knowledge workers create, structure and communicate information and knowledge. The field study findings have been used as input for a discussion of computer-support.

The results address requirements for knowledge networking media spaces, based on advanced information technological mechanisms like document archives, hypermedia spaces and other forms of shared repositories. We have argued that such support should be provided as mechanisms that augments and interconnects people and resources so that information and knowledge can be created, organised, distributed, exchanged and applied within a knowledge networking media space. We expect that such media spaces will reduce the complexity of articulating and distributing information and knowledge, and thereby form a usable and common information space, upon which collaborating actors effectively can manage knowledge in complex work settings.

In the process of moving towards requirements the discussions and requirements presented here is only a very first step. More elaborated inspections of the potentials in different technologies are required, and our findings and conclusions need further investigation.

\section{ACKNOWLEDGEMENTS}

This research work could not have been conducted without the invaluable help of the employees, who have been involved in the field study. The work presented here has partly been conducted within The Distibuted Multimedia Project (DMM) funded by the Danish research councils. Part of this research work has been funded by NorFA - The Nordic research and education academy.

\section{REFERENCES}

Ackerman, M. S. (1994), "Augmenting the Organizational Memeory: A field study of Answer Garden", in Proceedings of the ACM Conference in Computer Support Cooperative Work, pp 243-252, Boston, USA.

Ackerman, M. S, Halverson, K. (1998), "Considering an Organisation's Memory", in Proceedings of the ACM Conference in Computer Support Cooperative Work, CSCW '98, November, Seattle, Washington, US.

Ackerman, M. S, Malone, T. W. (1990), "Answer Garden: A Tool for Growing Organizational Memory", In IEEE Computer Society, Conference on Office Information Systems, Cambridge, Massachusetts, edited by Lochovsky, F. H., Allen, R. B., SIGOIS Bulletin, Vol 11, Issues 2, 3.

Bannon, Liam, and Susanne Bødker (1997): "Constructing Common Information Spaces," in The fifth European Conference on Computer Supported Cooperative Work, Lancaster, edited by J. A. Hughes at al., Kluwer Academic Publishers, 1997, pp. 81-96

Bucciarelli, Louis L. (1988): "An ethnographic perspective on engineering design," Design Studies, vol. 9, no. 3, July 1988, pp. 159-168.

Carstensen, Peter H. (1997): "Requirements for computerbased collaboration support for engineering designers," in Advances in Concurrent Engineering - CE97, August 2022, Oakland, Michigan, edited by S. Ganesan, Technomic, 1997, pp. 148-154.

Carstensen, Peter H. (1996): Computer Supported Coordination, Writings in Computer Science (No. 61), Department of Computer Science, Roskilde University, Roskilde, Denmark, 1996.

Carstensen, Peter H., and Volker Wulf (1998): "Common information spaces in engineering design: An analysis of the structure and use of a project file," in Advances in Concurrent Engineering - CE'98, Tokyo, edited by S. Fukuda and P. L. Chawdhry, Technomic, 1998, pp. 127135.

Conklin, J. E. (1998) Orgaizational Memory and QuestMap, http://www. gdss.com/OM.htm

Conklin, J, Begeman, M. L. (1988) "gIBIS: A Hypertext Tool for Exploratory Policy Discussion", In Proceedings of CSCW'88 Conference on Computer-Supported 
Cooperative Work, Portland, Oregon, September, NY, ACM Press, pp 140-152.1988

Conklin, J. E. (1996) Designing Orgaizational Memory: Preserving Intellectual Assets in a Knowledge Economy,. http://www.gdss.com/DOM.htm. 1996

De Michelis, G. (1997) "Cooperation and Knowledge Creation", In Comparative Study of Knowledge Creation, edited by Nonaka, I. \& Nishiguchi, T., Oxford University press, New York. 1997.

Firebaugh, M. W. (1989), Artificial Intelligence - A Knowledge-Based Approach. Boston: PWS-KENT Publishing Company.

Gaver, William, Abigail Sellen, Christian Heath, and Paul Luff (1993): "One is not enough: Multiple views in a media space," in INTERCHI'93 Conference on Human Factors in Computing Systems, Amsterdam, edited by S. Ashlund at al., ACM Press, 1993, pp. 335-341.

Gaver, William W., Gerda Smets, and Kees Overbecke (1995): "A virtual window on media space" CHI '95 Conference Proceedings. ACM Conference on Human Factors in Computing Systems, 7-11 May 1995, Denver, Colorado. New York: ACM Press, pp. 257-264.

Glance, N, Arregui, D, Dardenne, M. (1998), "Knowledge Pump: Supporting the Flow and Use of Knowledge", In Information technology for Knowledge Management, edited by Borghoff, U. M. \& Pareschi, R., Springer Verlag. 1998.

Huber, H. (1998), "Document Research based on collaborative provided structural Knolwedge", in Proceedings of th 2nd International Conference on Practical Aspects of Knowledge Management, edited by Reimer, U., Basel, Switserland

Hughes, J.A., Randall, D, Shapiro, D. (1993): "From ethnographic record to system design: Some experiences from the field", In Computer Supported Cooperative Work (CSCW), An International Journal, vol. 1, no. 3, pp. 123141

Keyser, Veronique De (1992): "Why field studies?," in Design for Manufacturability - A Systems Approach to Concurrent Engineering and Ergonomics, edited by M. Helander and M. Nagamachi, Taylor \& Francis, London, 1992, pp. 305-316.

Kirn, S. (1997), "Cooperative Knowledge Processing Research Framework and Application Perspectives", In Cooperative Knowledge Processing - The Key Technology for Intelligent Organisations, Springer Verlag. 1997.

Kristoffersen, S. (1996), "Organisational Memory - Support for Query Resolution in a Customer Service Center?", Technical Report CSEG/11/1996, at Lancaster University, UK

Kuuti, K, Virkkunen, J. (1994), "Organizational Memory and the Learning Network Organization: Perspectives from Cultural Historical Activity Theory", Chapter 5 In A Conceptual Framwork form Describing Organizations, COMIC Deliverable 1.2, October.

McDonald, D. W, Ackerman, M. S. (1998), "Just Talk to Me: A Field Study of Expertise Location", in Proceedings of $C S C W$ ' 98 , Seattle, Washington, US

Mentzas, G, Apostolou, D. (1998), "Managing Corporate Knowledge: A Comparative Analysis of Experiences in Consulting Firms", in Proceedings of th 2nd International Conference on Practical Aspects of Knowledge Management, edited by Reimer, U., Basel, Switserland
Nonaka, I., Takeuchi, H (1995).: The Knowledge-Creating Company - How Japanese Companies Create the Dynamics of Innovation, Oxford University Press, New York, US, 1995.

Orlikowski, W.J. (1992), "Learning from NOTES: Organisational Issues in Groupware Implementation", In Proceedings of $C S C W$ '92, Conference on ComputerSupported Cooperative Work, Toronto, Canada, ACM Press, pp. 362-369.

Patton, M. Q. (1980): Qualitative Evaluation Methods, Sage Publications, Beverly Hills, CA, 1980.

Robertson, M., S Sirensen, C, Swan, J. (1998) "Managing Knowledge with Groupware", in Proceedings of IRIS 21, Informations Systems Research seminar In Scandinavia, S3/4by, Danmark, 1998

Sandberg, J. (1992), Human Competence at Work - An interpretative approach, Doctorial dissertation, Handelshšgskolan vid Gøteborgs Universitet, BAS. 1994.

Schmidt, Kjeld (1994): Modes and Mechanisms of Interaction in Cooperative Work, RisÀ National Laboratory, P.O. Box 49, DK-4000 Roskilde, Denmark, 1994. [Ris À-R-666].

Schmidt, K., Bannon, L. (1992) "Taking CSCW Seriously Supporting Articulation Work", In Computer Supported Cooperative Work - An International Journal, Vol 1, No12, Kluwer Academic Publishers, pp 7-40. 1992.

Schmidt, Kjeld, and Peter Carstensen (1990): Arbejdsanalyse. Teori og praksis [Work Analysis. Theory and Practice], Risæ National Laboratory, DK-4000 Roskilde, Denmark, June, 1990. [RisÀ-M-2889].

Schmidt, Kjeld, and Carla Simone (1996): "Coordination Mechanisms: Towards a Conceptual Foundation of CSCW Systems Design," Computer Supported Cooperative Work. The Journal of Collaborative Computing, vol. 5, no. 2-3, 1996, pp. 155-200.

Snis, U. (1997), Kunskapsutveckling med sťsd av expertsystem [Knowledge creation by expert systems support], Licentiate Thesis, Paper 6, Department of Informatics, Gšteborgs Universitet, Sweden. 1997.

Spender, J.-C. (1998), "The Dynamics of Individual and Organisational Knowledge", In Managerial and Organisational Cognition - Theories, Methods and Research, edited by Eden, C. \& Spender, J.-C, SAGE Publications. 1998.

Van Heijst, G., van der Spek, R. \& Kruizinga, E. (1998): The Lessons Learned Cycle, in Information technology for Knowledge Management, edited by Borghoff, U. M. \& Pareschi, R., Springer Verlag, 1998.

Wathne, K., Roos, J. \& von Krogh, G. (1996): Towards a Theory of Knowledge Transfer in a Cooperative Context, in Managing Knowledge - Perspectives on cooperation and competition, edited by von Krogh, G. \& Roos, J., SAGE Publications, 1996. 